\title{
Development of Short Pulse Laser Pumped X-ray Lasers
}

\author{
J. Dunn, A. L. Osterheld, J. R. Hunter, V. N. Shlyaptsev
}

February 22, 2000

Lawrence

Livermore

National

Laboratory

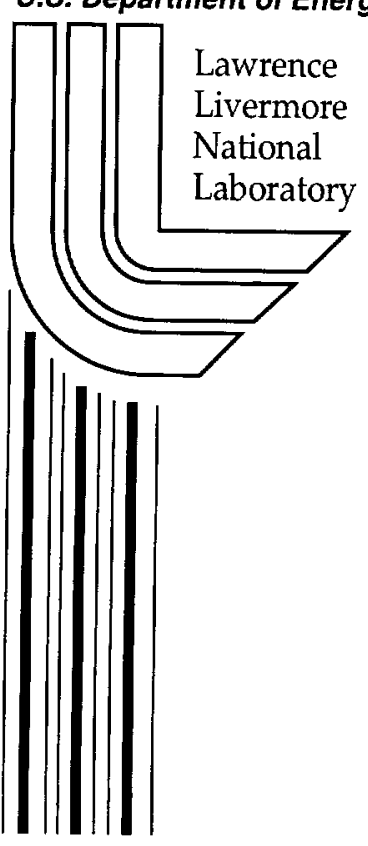




\section{DISCLAIMER}

This document was prepared as an account of work sponsored by an agency of the United States Government. Neither the United States Government nor the University of California nor any of their employees, makes any warranty, express or implied, or assumes any legal liability or responsibility for the accuracy, completeness, or usefulness of any information, apparatus, product, or process disclosed, or represents that its use would not infringe privately owned rights. Reference herein to any specific commercial product, process, or service by trade name, trademark, manufacturer, or otherwise, does not necessarily constitute or imply its endorsement, recommendation, or favoring by the United States Government or the University of California. The views and opinions of authors expressed herein do not necessarily state or reflect those of the United States Government or the University of California, and shall not be used for advertising or product endorsement purposes.

This work was performed under the auspices of the U.S. Department of Energy by the University of California, Lawrence Livermore National Laboratory under Contract No. W-7405-Eng-48.

This report has been reproduced directly from the best available copy.

Available electronically at http://www.doc.gov/bridge

Available for a processing fee to U.S. Department of Energy

And its contractors in paper from

U.S. Department of Energy

Office of Scientific and Technical Information

P.O. Box 62

Oak Ridge, TN 37831-0062

Telephone: (865) 576-8401

Facsimile: (865) 576-5728

E-mail: reports@adonis.osti.gov

Available for the sale to the public from

U.S. Department of Commerce

National Technical Information Service

5285 Port Royal Road

Springfield, VA 22161

Telephone: (800) 553-6847

Facsimile: (703) 605-6900

E-mail: orders@ntis.fedworld.gov

Online ordering: http://www.ntis.gov/ordering.htm

OR

Lawrence Livermore National Laboratory

Technical Information Department's Digital Library

http://www.llnl.gov/tid/Library.html 


\title{
Development of Short Pulse Laser Pumped X-ray Lasers
}

\author{
J. Dunn, A.L. Osterheld, J.R. Hunter ${ }^{1}$, and V.N. Shlyaptsev ${ }^{2}$ \\ V-Division, High-Energy Density Physics \\ ${ }^{1}$ New Technologies Engineering Division \\ ${ }^{2}$ Dept. of Applied Science, UC Davis-Livermore \\ Final Report for LDRD project 97-ERD-105
}

\section{Introduction}

X-ray lasers have been extensively studied around the world since the first laboratory demonstration on the Novette laser at LLNL in 1984 [1]. The characteristic properties of short wavelength, high monochromaticity, collimation and coherence make $\mathrm{x}$-ray lasers useful for various applications. These include demonstrations of biological imaging within the water window, interferometry of laser plasmas and radiography of laser-heated surfaces $[2-4]$.

One of the critical issues has been the high power pump required to produce the inversion. The power scaling as a function of $x$-ray laser wavelength follows a $\sim \lambda^{-4}$ to $\sim \lambda^{-6}$ law. The shortest $\mathrm{x}$-ray laser wavelength of $\sim 35 \AA$ demonstrated for Ni-like Au was at the limit of Nova laser capabilities [5]. By requiring large, high power lasers such as Nova, the shot rate and total number of shots available have limited the rapid development of x-ray lasers and applications. In fact over the last fifteen years the main thrust has been to develop more efficient, higher repetition rate $x$-ray lasers that can be readily scaled to shorter wavelengths. The recent state of progress in the field can be found in references $[6,7]$.

The objective of the project was to develop a soft x-ray laser (XRL) pumped by a short pulse laser of a few joules. In effect to demonstrate a robust, working tabletop x-ray laser at LLNL for the first time. The transient collisional scheme as proposed by Shlyaptsev et al [8, 9] was the candidate $x$-ray laser for study. The successful endeavour of any scientific investigation is often based upon prudent early decisions and the choice of this scheme was both sound and fruitful. It had been demonstrated very recently for Ne-like Ti at $326 \AA$ using a small tabletop laser [10] but had not yet reached its full potential. We chose this scheme for several reasons: (a) it was a collisional-type $\mathrm{x}$-ray laser which has been historically the most robust; (b) it had the promise of high efficiency and low energy threshold for lasing; (c) the principal architect of this laser (Dr. Shlyaptsev) was part of the team; (d) the laser driver requirements matched closely to the existing Physics facilities.

There were additional important reasons for study. The higher repetition rate and therefore total number of shots available in a smaller facility would allow a more complete characterization of the $\mathrm{x}$-ray laser properties. Optimized plasma irradiation conditions should then lead to the extraction of the maximum $x$-ray laser energy at the shortest possible wavelength. Also, tabletop XRLs are a relatively new phenomenon and so new transient $\sim 1$ ps timescale atomic kinetic physics could be studied. 
In the remainder of this report we give a brief summary of the LDRD activities and give concluding remarks with future directions. More details of the work can be found in the publications, proceedings and documents listed in the Appendix at the end of this report.

\section{Activities}

The goal of the initial experiments in 1997 was to produce tabletop lasing using the Janus-ps laser. The basic infrastructure including laser system and target chamber was already in place. However, the laser driver characteristics including beam profile, output energy and diagnostics all required substantial improvement to meet the $x$-ray laser pumping requirements. Since the transient scheme requires the sequential heating of a solid with a long pulse followed by a short pulse laser [9], a long pulse was also required. Target chamber optics had to be designed, procured and setup for a two beam line focus. X-ray diagnostics including $\mathrm{x}$-ray slit cameras, crystal spectrometers and soft $\mathrm{x}$-ray spectrometers had to be designed, fabricated and installed.

The chirped pulse amplification Janus-ps laser was optimized to better fill the amplifiers to maximize the output energy before compression. The beam diameter was increased to 8.5 $\mathrm{cm}$ to deliver this energy to the target chamber while keeping the fluence below the damage threshold of the Au-coated compressor gratings. Maximum energy of $7.5 \mathrm{~J}$ EOT in a $500 \mathrm{fs}$ (FWHM) pulse, 15 TW peak power capability, was achieved at a repetition rate of 1 shot/4 minutes. Rod shots $\sim 5 \mathrm{~J}$ energy in 800 ps from the Janus laser provided the long pulse with a similar repetition rate. The Janus laser was synchronized with the Janus-ps oscillator with an acceptable 100 ps r.m.s. jitter. The two laser pulses were co-propagated down a single beam path. An alignment imaging system and telescope was implemented to aid the repeatable positioning of the beams on target. A combination of a $f=4 \mathrm{~m}$ cylindrical lens and a $f=0.61 \mathrm{~m}$ paraboloid optics were chosen to produce a line focus of $1.2 \mathrm{~cm}$ long $\times 100 \mu \mathrm{m}$ wide. Nominal irradiances of $10^{12} \mathrm{~W} \mathrm{~cm}^{-2}$ and $7 \times 10^{14} \mathrm{~W} \mathrm{~cm}^{-2}$ could be produced on a $1 \mathrm{~cm}$ long target. Polished metal slab targets were laser cut to the desired shape. All x-ray diagnostics used low noise, high dynamic range $\mathrm{CCD}$ detectors designed and fabricated inhouse. The combination of these features allowed a high shot rate and maximized the data acquisition rate for the experiments.

After initial attempts to generate an $\mathrm{x}$-ray laser, the first success was achieved for Ne-like Ti at $326 \AA$ on June 3, 1997. Subsequent optimization of the plasma conditions generated very strong lasing on the $3 p-3$ s transition shown in Fig. 1(a). The desired exponentiation of the $326 \AA$ transition can be seen with small millimeter changes in the irradiated target length in Fig. 1(b). A small-signal gain coefficient of $24 \mathrm{~cm}^{-1}$ was determined from the experimental data. To put this into perspective, previous Nova XRL experiments typically had small-signal gains of $4 \mathrm{~cm}^{-1}$. Shortly after this, we chose to study palladium $\mathrm{Z}=46$ as a possible medium $Z$ nickellike ion to achieve a shorter wavelength XRL. A simplified energy level diagram is shown in Fig. 2(a). The upper $4 \mathrm{~d} J=0$ level is pumped directly from the ground state by transient collisional excitation thus producing the transient population inversion between the $4 \mathrm{~d}$ and $4 \mathrm{p}$ levels. We observed the Ni-like Pd $4 \mathrm{~d}-4 \mathrm{p} \mathrm{J}=0-1$ transition to lase at $147 \AA$ as shown in Fig. 2(b) for a $6 \mathrm{~mm}$ polished slab target irradiated with $5.7 \mathrm{~J}$ of $800 \mathrm{ps}$ and $5.2 \mathrm{~J}$ of $1.1 \mathrm{ps}$ duration pulses. The line is measured in first and second 
order; no other lasing lines are visible in the spectrum. The structure observed to the short wavelength side of $250 \AA$ in Fig. 2(b) is identified as the Si L-edge at $\sim 123 \AA$ in second order from surface layers on the back-thinned CCD detector.
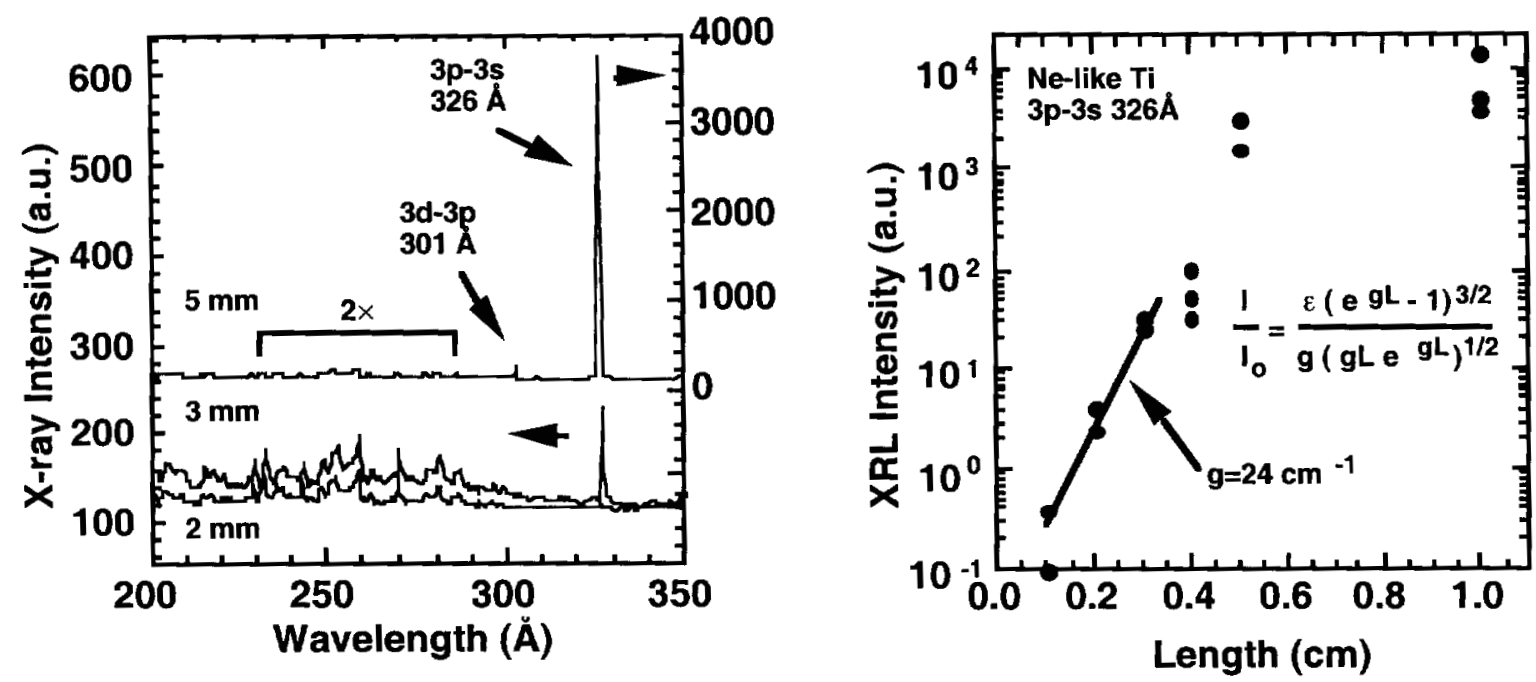

Fig. 1 (a) (left) shows the spectrum for Ne-like Ti for 2, 3 and $5 \mathrm{~mm}$ target lengths. The Ne-like $3 \mathrm{p}-3 \mathrm{~s}$ line is indicated at $326 \AA$ and strongly increases with target length. Note the change in intensity scale on the right hand side for the $5 \mathrm{~mm}$ target length. The $3 \mathrm{~d}-3 \mathrm{p}$ line at $301 \AA$ is also labeled. (b) (right) is a plot of the $326 \AA$ XRL output as a function of target length up to $10 \mathrm{~mm}$. A gain of $24 \mathrm{~cm}^{-1}$ is established by fitting up to target length $3 \mathrm{~mm}$.
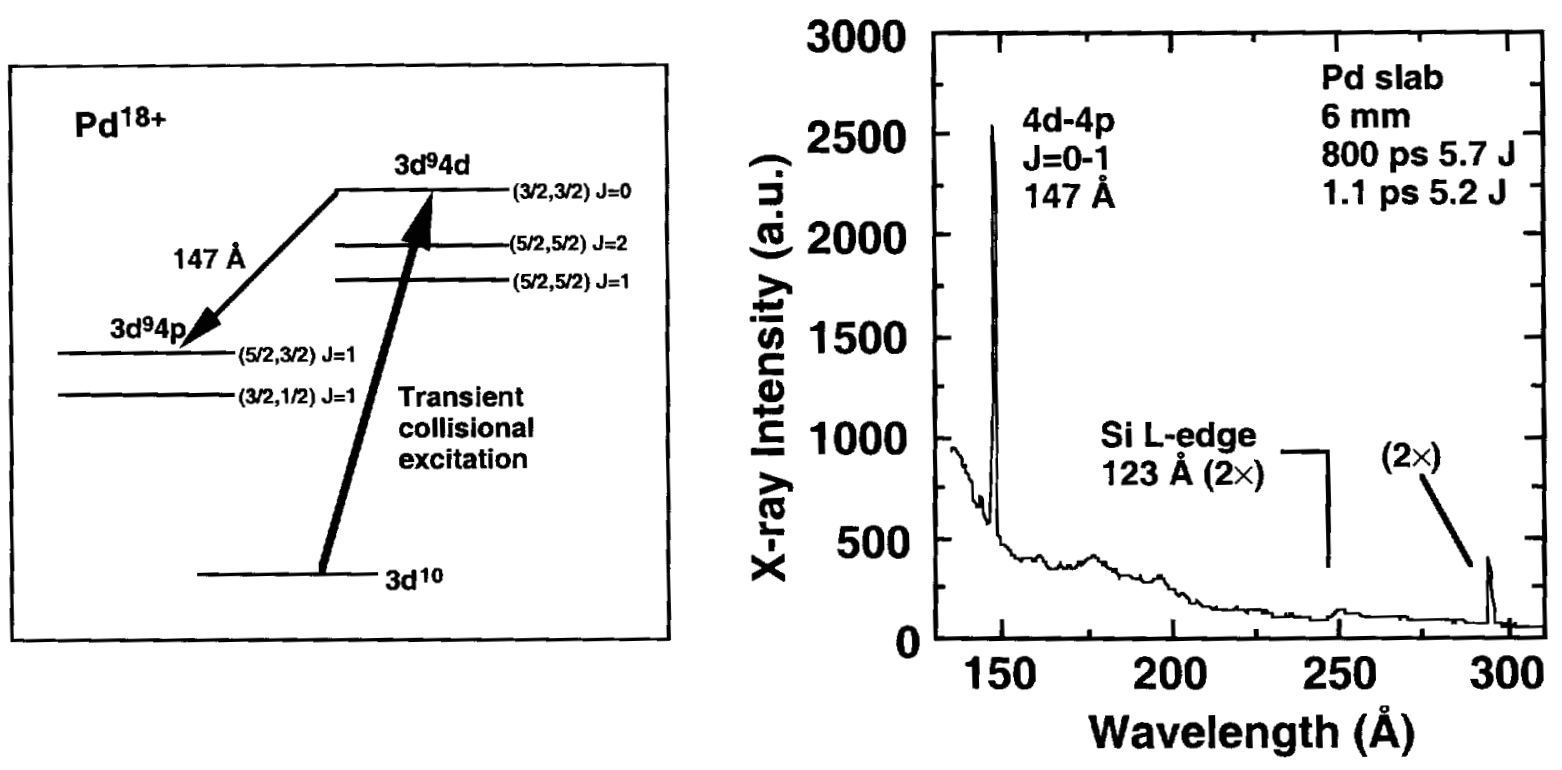

Fig.2 (a) (left) shows a simplified energy level diagram for Ni-like Pd. (b) (right) shows a Ni-like Pd spectrum for a $6 \mathrm{~mm}$ target with the $147 \AA$ XRL line observed in first and second order. 
The significance of the Ni-like Pd lasing was obvious. Medium Z Ni-like ions lased extremely well with high gains $\sim 35 \mathrm{~cm}^{-1}$ and allowed access to the shorter wavelength regime with the same driver energy. This was the most important result in 1997.

It was found that a critical parameter for Ne-like Ti lasing was the delay between the laser driver pulses $\Delta \tau$, where $\Delta \tau$ is defined as the peak-to-peak arrival time of the short pulse after the long pulse, for a given long pulse energy. The window for good lasing conditions was found to occur between $1 \mathrm{~ns}$ and $2 \mathrm{~ns}$ with the optimum centered fairly narrowly at $\sim 1.6 \mathrm{~ns}$. In fact, for $\sim 5 \mathrm{~J}$ long pulse energy no $\mathrm{x}$-ray laser was observed for a delay $\Delta \tau$ of less than 800 ps. The experimental data of $\mathrm{x}$-ray laser intensity as a function of delay between the two laser pulses is plotted in Fig. 3. This issue was known but not investigated systematically in the experiments of other groups. Extensive modeling of the laser plasma conditions was conducted with the RADEX code to fully understand this phenomena.

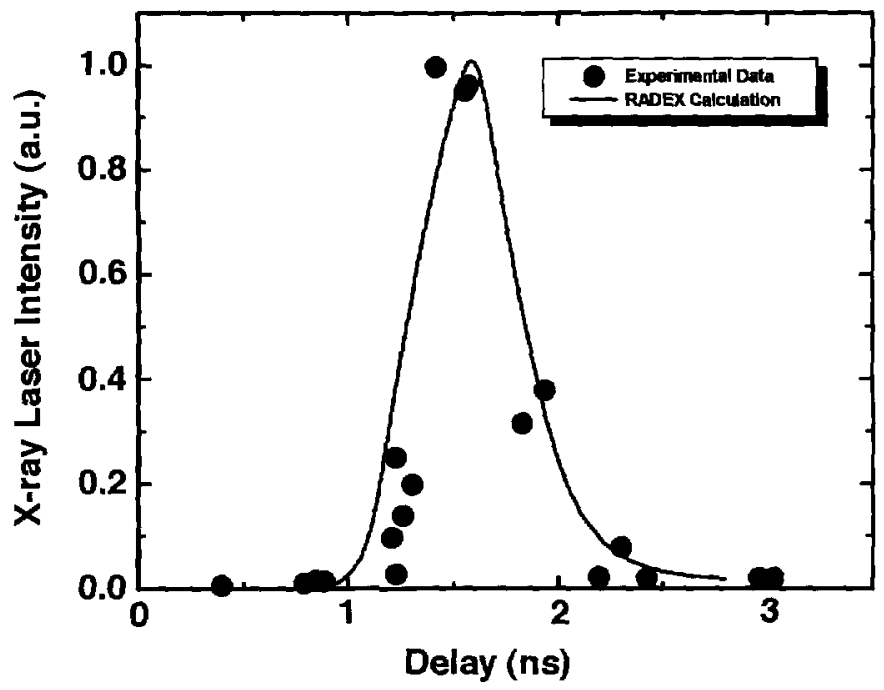

Fig.3 Experimental measurements of the $326 \AA$ Ne-like Ti $3 p-3 s \quad J=0-1$ x-ray laser intensity (full circles) as a function of delayed arrival of the short pulse relative to the peak long pulse. Strong lasing is observed at a delay of $1.6 \mathrm{~ns}$. Full curve shows comparison from the one-dimensional numerical code RADEX for the experimental lasing conditions.

The 1-dimensional numerical code RADEX treats the transient hydrodynamics, atomic kinetics and radiation transport self-consistently [8,9]. An additional ray-tracing package, as a post-processor, is used to model the propagation of the $\mathrm{x}$-ray laser along the gain medium and calculate the $x$-ray laser intensity. It is important to note that the hydrodynamics, atomic kinetics and ray-tracing have to be made using a transient approximation to simulate the experimental conditions. In particular, calculations show that if the x-ray laser line raytracing is made in a quasi-steady state approximation for gain described as transient this produces results inconsistent with the observed $x$-ray laser characteristics including the lasing intensity, pulse duration, deflection angle and effective gain. This can be explained mainly by the fast gain risetime of $1-3 p s$ and short lifetime of $5-15$ ps (for plasma 
densities $n_{e} \sim 1-3 \times 10^{20} \mathrm{~cm}^{-3}$ ) compared to the propagation time $L / c \sim 30 \mathrm{ps}$ along the amplified medium. The major observed XRL characteristics are consistent with the experiment only when the effects of fast temporal evolution of the gain and photon transit time are included and properly described.

An explanation of the long pulse-to-short pulse delay was one of the important questions to be answered for effective laser operation in the transient regime. There exists a similarity here with previous experiments for pre-pulse formed x-ray laser plasmas in the quasi-steady state (QSS) regime. It was found in many experiments mostly conducted by Nilsen et al [11] that the QSS lasing could be maximized with different kinds of low density pre-pulses, multiple pulses of different duration, with optimal energies and delays. These experiments were driven by $150 \mathrm{~J}$ to $>1000 \mathrm{~J}$ laser energy. The main conclusion was that enhanced laser action was a result of substantial suppression of refraction. There are several new aspects in the fundamental operation for the transient excitation scheme. Hence the optimized parameters are significantly different from the previous QSS approach. A number of comparisons have been made for the experimental data and the code RADEX simulations at the same conditions for different atomic elements.

Referring to Fig. 3, it can be seen that lasing does not occur if the picosecond pulse arrives earlier than $1.0-1.2 \mathrm{~ns}$ after the long pulse. There is a window where good lasing is observed, centered at $\sim 1.6 \mathrm{~ns}$, followed by a fast decrease for delays of more than $2.2 \mathrm{~ns}$. This non-lasing early delay behavior is more than just strong refraction effects at the beginning of expansion. This is confirmed in the simulations by artificially reducing the effects of refraction by an order of magnitude: the time of optimal delay and width of lasing window remain relatively unchanged. The additional reason why lasing does not appear prior to a specific moment lies in the physics of the transient inversion. To achieve substantial transient gain, the initial plasma temperature before the picosecond temperature jump must be low enough to empty all excited level populations. After the 800 ps pulse has finished, the laser plasma is allowed to cool down by expansion and radiation to reach less than $80 \mathrm{eV}$ for $\mathrm{Ti}$ and less than $90 \mathrm{eV}$ for Pd. Unless these conditions are achieved the transient gain is small. The fall in XRL intensity for large delays is due to substantial plasma expansion and the resultant drop in the density. This causes in turn a decrease in the short pulse laser absorption and hence reduced plasma temperatures during the short pulse. At these late delays the density and corresponding gradients are reduced by more than $50 \%$ which is beneficial for refraction effects but is not sufficient to compensate for the lower gain coefficient. Optimization of the XRL output was required for each ion and involved adjustment of the long pulse energy/delay parameters.

The Janus-ps laser was required for a different experiment from July to November 1997 and was unavailable for $\mathrm{x}$-ray laser experiments in this time. Further analysis, modeling and interpretation of the data were performed.

\section{Activities 1998}

The Janus laser was in demand when the x-ray laser studies were resumed in 1998. A reconfiguration of the x-ray laser drivers was essential for further timely progress of the LDRD work. De-coupling the short pulse laser from Janus and installing an additional long 
pulse amplifier on the same table would give a dedicated tabletop, $x$-ray laser facility. To achieve this, an additional $50 \mathrm{~mm}$ diameter rod amplifier was built on the second short pulse laser table. The amplified stretched laser pulse after the $25 \mathrm{~mm}$ rod amplifier was split into a long pulse and short pulse arm with each being amplified in a separate, double-passed 50 $\mathrm{mm}$ rod amplifier. The long pulse arm would remain stretched at 600 ps (FWHM) duration with the delay between the two laser pulses adjustable so that the 1 ps pulse could arrive between 0 and 2 ns after the long pulse. The tabletop laser was now a stand-alone facility and was named the Compact Multipulse Terawatt or COMET laser. At this time a pre-pulse forming network was installed to generate an optional pre-pulse in front of the long pulse to help absorption and improve plasma density gradients. The laser driver and shot parameters are listed in Table 1.

\begin{tabular}{|l|l|}
\hline Parameter & \\
\hline Long Pulse $(1053 \mathrm{~nm})$ & $600 \mathrm{ps}($ FWHM $), 15 \mathrm{~J}$ EOT \\
\hline Short Pulse $(1053 \mathrm{~nm})$ & $500 \mathrm{fs}-10 \mathrm{ps}($ FWHM $), 7.5 \mathrm{~J}$ EOT \\
\hline Peak Power & $15 \mathrm{TW}(7.5 \mathrm{~J}$ EOT in $500 \mathrm{fs})$ \\
\hline Optional pre-pulse & $6 \%$ of main pulse, $2 \mathrm{~ns}$ early \\
\hline Beam Diameter & $8.4 \mathrm{~cm}$ \\
\hline Line Focus & $25-100 \mu \mathrm{m} \times 12.5 \mathrm{~mm}(\mathrm{~W} \times \mathrm{L})$ \\
\hline Laser Shot Rate & 1 shot $/ 4$ minutes \\
\hline
\end{tabular}

Table 1. COMET Laser Driver and Shot Parameters

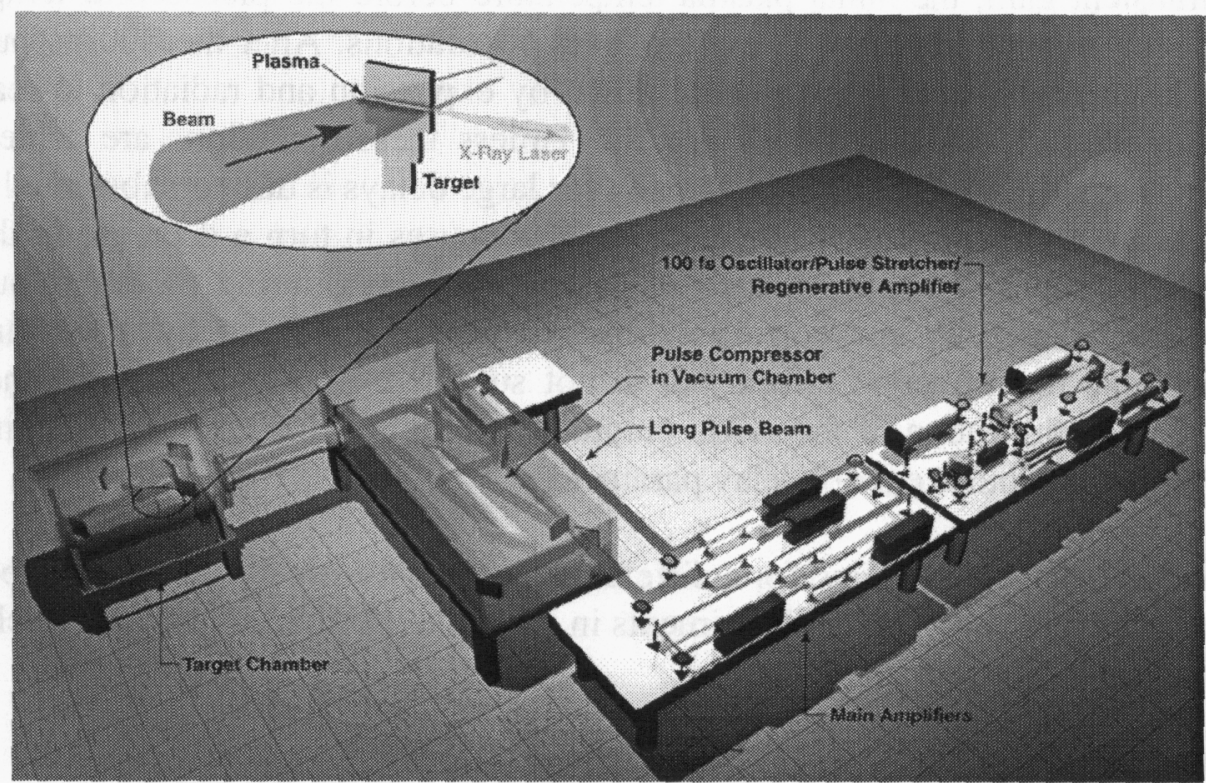

Fig.4 Rendering of the Compact Multipulse Terawatt (COMET) laser. The laser occupies two standard optical tables of dimensions $1.2 \mathrm{~m} \times 3.6 \mathrm{~m}$. 
A rendering of the laser system is shown in Fig. 4. One of the main advantages of the laser system was the jitter-free synchronization of the two laser pulses. In keeping with the previous studies the short pulse was lengthened slightly to $1.1 \mathrm{ps}$.

The first experiments with the COMET laser facility were performed using $\mathrm{Ti}$ and $\mathrm{V}$ targets in order to drive inversions on the Ne-like ion $3 p \rightarrow$ $3 s J=0 \rightarrow 1$ transitions at $326 \AA$ and $304.5 \AA$, respectively. The main goal was to determine how close to saturated output were the amplified transitions. Slab targets up to $1 \mathrm{~cm}$ were irradiated with $\sim 5 \mathrm{~J}$ in a 600 ps (FWHM) plasma forming pulse and $\sim 5 \mathrm{~J}$ in a 1.1 ps (FWHM) excitation pulse. Both materials lased strongly giving similar outputs when the arrival of the short pulse was delayed by $1.5 \mathrm{~ns}$ peak-to-peak relative to the long pulse. This is in agreement

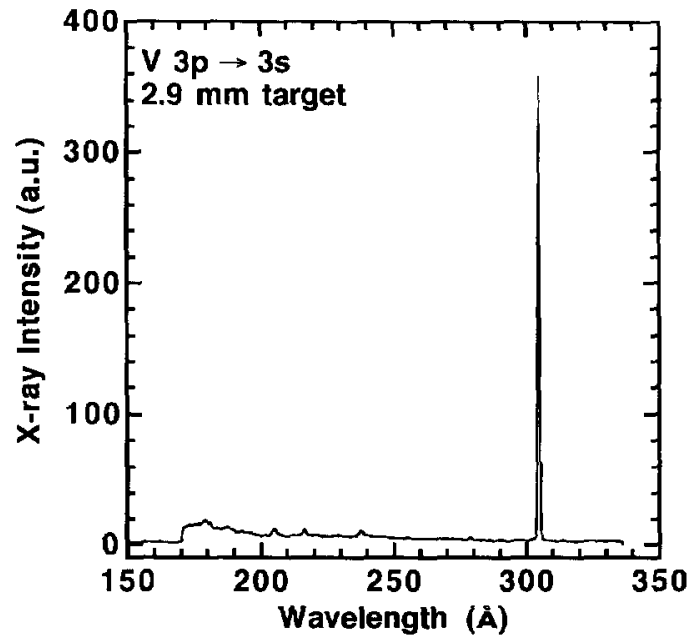

Fig.5 X-ray laser spectrum for $2.9 \mathrm{~mm}$ vanadium target irradiated by $5.8 \mathrm{~J}, 580$ ps and $5.5 \mathrm{~J}, 1.1$ ps pulses. Ne-like $3 p$ $\rightarrow 3 s$ line at $304.5 \AA$ dominates the spectrum. with our previous results for Ti using the JANUS long pulse despite the different pulse shapes and durations. To put this in perspective, there have been other laser-produced plasma experiments showing Ne-like $\mathrm{V}$ lasing. An experiment conducted at the Max Plank Institute on the Asterix IV iodine laser reported a stronger short wavelength $3 p \rightarrow 3 s J=0$ $\rightarrow 1$ transition at $263 \AA$ in addition to the long wavelength $304.5 \AA$, see $\mathrm{Li}$ et al [12]. The prepulse technique was used where a $15 \%$ prepulse arrived $\sim 5 \mathrm{~ns}$ in front of the main laser pulse of 450 ps duration with $\sim 500 \mathrm{~J}$ total energy on a $2.5 \mathrm{~cm} \mathrm{~V}$ target. The long wavelength vanadium $J$ $=0 \rightarrow 1$ line also had reduced intensity. This anomalous lasing for vanadium was in contrast to target materials from adjacent atomic numbers irradiated under similar conditions: the short wavelength $J=0 \rightarrow 1$ line in the adjacent isoelectronic sequence was orders of magnitude weaker. Recently Nickles et al. observed transient gain on the long wavelength $J=0 \rightarrow 1$ transition for target lengths up to $5 \mathrm{~mm} \mathrm{[11].} \mathrm{There} \mathrm{was} \mathrm{no}$ indication of lasing on the short wavelength line or any other transition.

A detailed study of vanadium to measure the

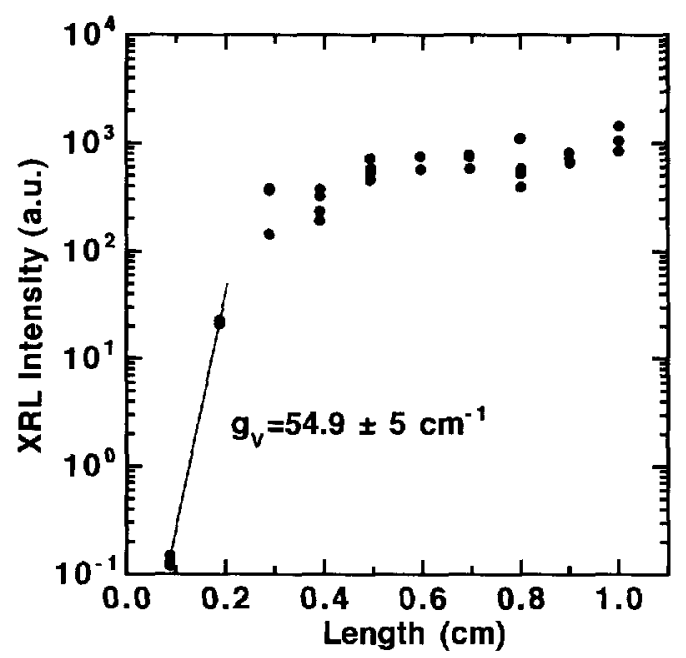

Fig.6 Intensity versus length plot for the Nelike V $3 p \rightarrow 3 s J=0 \rightarrow 1$ x-ray laser at $304.5 \AA$. Small-signal gains $\sim 55$ $\mathrm{cm}^{-1}$ are determined for short target lengths up to $3 \mathrm{~mm}$. $x$-ray laser gain characteristics and estimate the overall gL prduct. Flat stepped length targets varying from 1 to $10 \mathrm{~mm}$ in increments of 1 $\mathrm{mm}$ were irradiated by the two laser pulses. A $2000 \AA \mathrm{Al}$ filter was placed in front of the spectrometer to reduce higher order grating reflections overlapping the first order. The $\mathrm{x}$-ray 
laser output was sufficiently strong to drive the CCD detector into saturation and required some attenuation. Fig. 5 shows a single-shot spectrum from the on-axis spectrometer for a short $2.9 \mathrm{~mm}$ target: strong lasing action on the long wavelength $3 p \rightarrow 3 s$ line at $304.5 \AA$ is visible and is many orders of magnitude higher than any other line. The total laser energy irradiating the $2.9 \mathrm{~mm}$ long target is only $2.6 \mathrm{~J}$ which shows the significantly reduced energy requirement and high efficiency for the transient collisional excitation scheme. This indicates that the transient scheme is on the verge of being driven at higher repetition rates e.g. $10 \mathrm{~Hz}$ by present state-of-the-art laser systems.

Two weaker lines are observed in the spectrum but are not labeled: the short wavelength $J=0 \rightarrow 1$ line is measured at $261.3 \AA$ and is a factor of 500 times less intense compared with the main laser line. There is no anomalous lasing for the short wavelength $J=0 \rightarrow 1$ line under these transient gain conditions which is in agreement with observed weak lasing of this transition for $\mathrm{Ti}$ and Fe targets. The Ne-like $\mathrm{V} 3 d \rightarrow 3 p J=1 \rightarrow 1$ transition measured at $278.4 \AA$, just visible in Fig. 5, is about 100 times weaker than the main line. Lasing on the $3 d \rightarrow 3 p$ line has been observed and predicted for Ti but this is the first time that it has been observed for vanadium or higher atomic number.

Fig. 6 shows the intensity versus length data for the vanadium $304.5 \AA$ lasing line. Many laser shots, three or more data points per target length, with energy held constant were used on target and excellent reproducibility of the lasing line was observed. The intensity curve can be described as having a region of ultra-high gain for short target lengths below $3 \mathrm{~mm}$ rapidly rolling over to lower gain for longer target lengths up to $1 \mathrm{~cm}$. Applying the Linford formula [13] to fit the high gain region, an extremely high smallsignal gain of $55 \mathrm{~cm}^{-1}$ are inferred from the data with a gain-length product of 12.7 for the $2.9 \mathrm{~mm}$ target. The laser output continues to increase at a lower exponential rate with a $g L \sim 14.6 \pm 0.5$ at $1 \mathrm{~cm}$. While this was estimated to be close to saturation intensity, further experimental activities were required to improve the output and explain the behavior of the gain curve.

At the same time we attempted to drive a lower $\mathrm{Z} \mathrm{Ni}$-like ion $4 d \rightarrow 4 p$ transition into saturation with the expectation that this could be achieved with a lower energy drive. This was a reasonable assumption since the ionization and excitation temperature conditions were significantly lower than the longer wavelength $\mathrm{Ne}$-like ion $\mathrm{x}$-ray lasers that had been successfully pumped by the traansient scheme. However, no $x$-ray lasing at $\sim 200 \AA$ had been observed previously. We

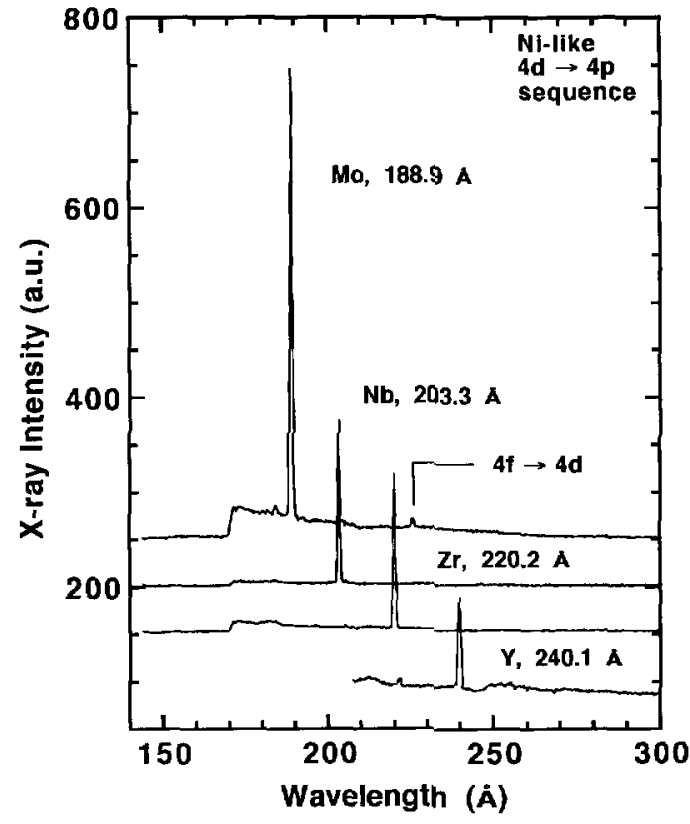

Fig. 7 On-axis spectrum of $0.8 \mathrm{~cm}$ slab targets of $\mathrm{Y}, \mathrm{Zr}, \mathrm{Nb}$, and $\mathrm{Mo}$ showing the $\mathrm{Ni}$ like $4 d{ }^{1} S_{0} \rightarrow 4 p{ }^{1} P_{\mathrm{I}}$ lasing transition clearly visible on each material. The weaker $4 f^{1} P_{1} \rightarrow 4 d^{1} P_{1}$ laser transition of Ni-like Mo at $225.9 \AA$ is labeled. 
found that experiments on these materials produced strong lasing as shown in the spectra of Fig. 7 after careful optimization had been performed. On-axis single laser shot spectra show the emission from $0.8 \mathrm{~cm}$ slab targets of $\mathrm{Y}, \mathrm{Zr}, \mathrm{Nb}$, and Mo. A $2000 \AA \mathrm{Al}$ filter was used in front of the spectrometer for the molybdenum, niobium and zirconium spectra giving rise to the L-edge structure at $170 \AA$. The strong Ni-like $4 d{ }^{1} S_{0} \rightarrow 4 p{ }^{1} P_{1}$ x-ray laser transition is clearly visible on each material. Laser driver energies on target were $0.3 \mathrm{~J}$ in $600 \mathrm{ps}$ and 4.6 $\mathrm{J}$ in $1.1 \mathrm{ps}$ for the yttrium and niobium targets. Slightly higher energies of $\sim 1 \mathrm{~J}$ in the long pulse and $5 \mathrm{~J}$ in the short pulse were used for the zirconium and molybdenum targets, shown here. A limited number of shots were tried on the $\mathrm{Y}$ target and so further enhancement of the line intensity should be possible. The wavelengths of the $4 d \rightarrow 4 p$ lasing lines were accurately measured. In addition, the $4 f^{1} P_{1} \rightarrow 4 d^{1} P_{1}$ x-ray laser transition of Ni-like Mo at $225.9 \AA$ was observed and labeled in Fig. 4. This transition is the analogue of the Ne-like $3 d \rightarrow 3 p$ transition and is populated by collisional excitation and selfphotopumping by the $4 f \rightarrow 3 d$ resonance line as described recently by Nilsen [14]. In spite of showing promise as a more efficient $\mathrm{x}$-ray laser we were unable to match the output of the Ne-like ion XRLs. Further modeling and interpretation of the gain curves for the Ne-like and Ni-like XRLs suggested some form of traveling wave along the line focus was essential. This would ameliorate the decaying gain conditions experienced by the $x$-ray beam as it propagated along the plasma medium.

\section{Activities 1999}

The final year of the LDRD involved several campaigns focusing on key aspects of the $\mathrm{X}$ ray laser development in particular achieving a saturated output. These included the implementation of a traveling wave line focus, a characterization study of the line focus uniformity, Ne-like ionization conditions and 2-D gain region imaging using $\mathrm{Mo}: \mathrm{Si}$ multilayer coated optics. The

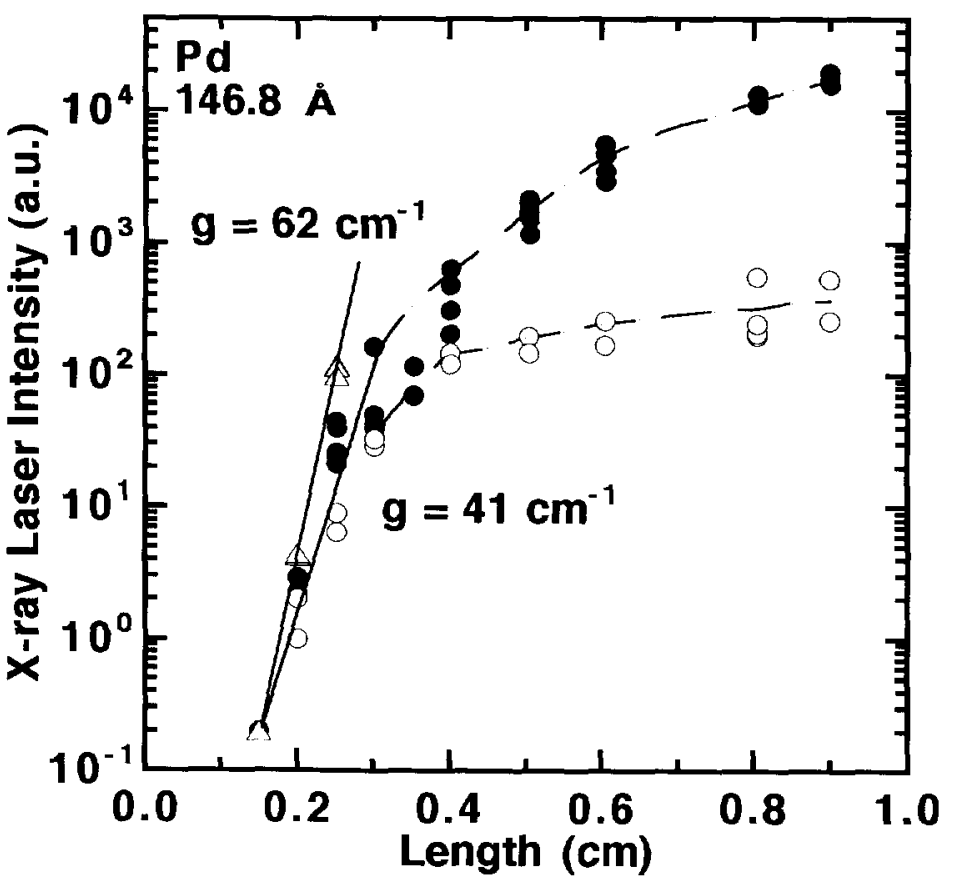

Fig. 8 Intensity versus length plot for Ni-like $\mathrm{Pd} 4 d \rightarrow 4 p$ x-ray laser line. Nominal experimental conditions are $2 \mathrm{~J}, 600$ ps and $4.8 \mathrm{~J}, 1$ ps of energy in line focus for traveling wave (full circles) and no traveling wave (open circles). The dashed curve is to guide the eye. Gain of $41 \mathrm{~cm}^{-1}$ (solid line) is determined at short target lengths for traveling wave and approximately $35 \mathrm{~cm}^{-1}$ for no traveling wave. Traveling wave with $0.5 \mathrm{~J}$ energy in $600 \mathrm{ps}$ (triangles) has higher gain $62 \mathrm{~cm}^{-1}$ (solid line).

main objectives were to: (a) maximize the output of the X-ray laser; (b) determine the beam characteristics in particular collimation, and gain region dimensions; (c) determine the repeatability of output and robustness. These were essential for the use of the tabletop XRL for future applications. 
A traveling wave excitation (TWE) scheme was implemented by using a relatively simple technique of a 5segment reflection echelon. This was placed at normal incidence in the beam path inside the target chamber immediately before the focusing optics. By offsetting each segment by approximately $1 \mathrm{~mm}$ relative to its neighbor portions of the beam were delayed to generate a traveling wave or sequentially delayed laser pulse arriving along the line focus. In this way, as the $\mathrm{X}$-ray laser propagated along the plasma column the excitation of the short pulse would be matched in time to maintain high gain conditions. A nominal $1 c$ setup was used. The effect of this traveling wave was studied for a number of Ne-like and Ni-like ion $\mathrm{x}$ ray lasers. In all cases a dramatic increase in output was observed, particularly for the $\mathrm{Ni}$-like ions where increases of $20-100 \times$ were common. Fig. 8 shows the increase of the Ni-like Pd XRL with increasing target length with and without the TWE. For target lengths of $3 \mathrm{~mm}$, the traveling wave XRL output is slightly higher and shows higher gain. However, the major advantage of the TWE scheme is apparent for longer plasmas where the XRL is observed to continue to experience higher exponentiation. Without the TWE results in the XRL output effectively remaining constant with increasing target length. For target lengths approaching $1 \mathrm{~cm}$ the TWE scheme is two orders of magnitude more intense. Estimates of the XRL intensity from the simulations indicate that the XRL is well into the saturation regime with outputs $>10 \mu \mathrm{J}$.

Extensive study of the near-field XRL beam profile of the $189 \AA \mathrm{Ni}$-like Mo line was performed. Two examples are shown in Fig. 9 to illustrate the variation in the near-field pattern for different laser irradiation conditions. The laser parameters have been set to give optimum output intensity for the laser. The laser is incident from the left, the initial target surface is at $z=0$ and the imaging system is viewing the end of the target as the XRL exits the plasma. Increasing the long pulse laser energy correspondingly increases the dimension of the XRL profile away from the target. The XRL dimension along the $y$-axis is defined by 
the short pulse focus width of $90 \mu \mathrm{m}$ (FWHM). The XRL output was higher with the larger long pulse energy. These beam profiles were repeatable and generally smooth profiles.

The far-field image pattern for the $x$-ray laser was not studied with the multilayer imaging system. However, these characteristics could be studied for the horizontal direction at a propagation distance of $1 \mathrm{~m}$ using the on-axis spectrometer. The XRL beam divergence and deflection angles are a sensitive indicator of refraction effects as the ray propagates through plasma density gradients perpendicular to the target surface. Fig. 10 shows the results of these angular measurements as a function of target length for the $147 \AA \mathrm{Pd}$ laser. As the $\mathrm{x}$-ray laser is driven into saturation for plasma lengths of $>5 \mathrm{~mm}$ progressive narrowing of the beam divergence and reduction of the deflection angle are observed. Typical minimum beam divergence of $3-5 \mathrm{mrad}$ (FWHM) are noted with deflection angles of 2 - 5 mrad away from the target surface. The RADEX ray tracing simulations are in good agreement with the experimental values and even show the subtle angular re-broadening effects at the long plasma lengths. Smaller beam divergences approaching 2 mrads have been demonstrated for the Ag laser.

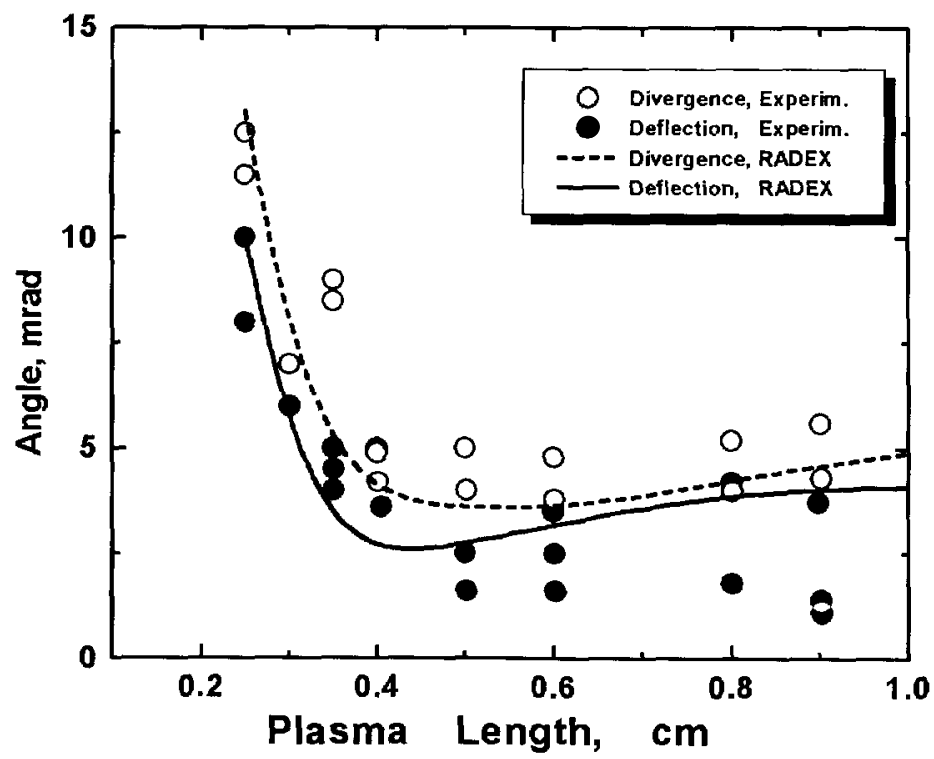

Fig. 10 Beam deflection (full circles) and divergence (open circles) of the Pd $\mathrm{x}$-ray laser with plasma length in comparison with RADEX calculations (solid and dash lines, respectively).

Fig. 11 gives the typical spectra for a number of Ni-like ion $\mathrm{x}$-ray laser lines operating between 100 and $200 \AA$ driven with the TWE irradiation. Total energy in the line focus is 5 - $7 \mathrm{~J}$. The Mo, Pd, and $\mathrm{Ag} \mathrm{x}$-ray laser lines are operating above the saturation intensity and show intense, single line features. Cd and $\mathrm{Sn}$ XRLs have lower output which indicates that the excitation process needs further enhancement for these shorter wavelngth XRLs. 


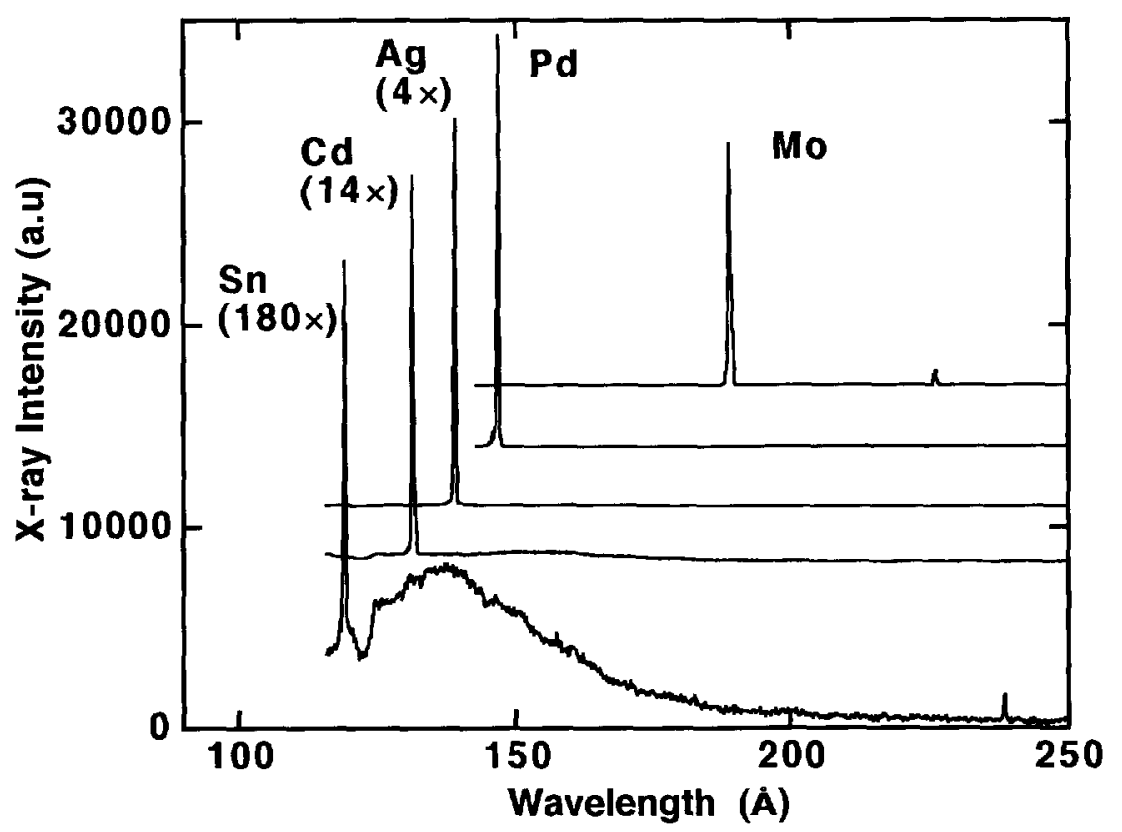

Fig. 11 Typical single shot spectra from the Ni-like ion sequence from Mo to Sn. Total laser energy in the line focus is between 5 and $7 \mathrm{~J}$. In each case the strong $4 d \rightarrow 4 p$ x-ray laser line from 189 to $119 \AA$ dominates the spectrum. Note that the baseline of all spectra except $\mathrm{Sn}$ are offset for clarity. Ag, Cd and $\mathrm{Sn}$ have intensity multipliers of $4 \times, 14 \times$, and $180 \times$ respectively, to normalize the line intensity.

In conclusion, we have successfully investigated a tabletop x-ray laser in theory and experiments. We have driven a number of Ni-like and Ne-like X-ray lasers into saturation with in excess of $10 \mu \mathrm{J}$ of laser output energy. Detailed characterization of the plasma conditions have been essential to understand the mechanisms for achieving optimum lasing. Small changes to the present line focus geometry will produce XRL outputs approaching 50 $-100 \mu \mathrm{J}$. Considering that kilojoule laser energies a few years ago were required to generate an XRL these results are remarkable for a small laser driver of $\sim 10 \mathrm{~J}$. Table 2 below compares the laser and XRL parameters for COMET and Nova. The benefit of the higher repetition rate and lower cost of tabletop laser are significant. Higher repetition rates for laser driven schemes should be possible in the very near future. It should be noted that the brightness of the tabletop XRL is comparable with the Nova XRL largely because of the shorter pulse duration and better collimation.

The shortest $\mathrm{X}$-ray laser wavelength achieved so far on the COMET laser has been $\mathrm{Ni}$ like $\mathrm{Sn}$ at $119 \AA$. In principle, with better coupling of the laser energy into the plasma shorter wavelength $\mathrm{x}$-ray lasers should be possible. There are other avenues, in particular improving laser absorption with low density targets, that have not been explored in this work which would be expected to give further efficiency enhancements. However, this is less of an issue for possible uses of the tabletop XRL since many of the demonstration applications on larger laser facilities like Nova have used Ne-like XRLs at $155 \AA$ and $196 \AA$. The existing Ni-like ion x-ray lasers operating near $140 \AA$ are ideal for a number of applications mainly because they are well-suited to high-reflectivity Mo:Si multilayer coated optics. The properties of the tabletop XRL, e.g. near-field profile, beam divergence and pointing angles are very promising. These characteristics and the output energy are very 
repeatable on a shot-to-shot basis. We have demonstrated use of multilayer optics for characterizing the x-ray laser near-field beam properties. The next step would be to probe a high density plasma with the $x$-ray laser. Plans for this are under way. The transient collisional excitation $x$-ray laser is an important tool and such a diagnostic could be set up for future experiments for probing NIF plasmas.

\begin{tabular}{|c|c|c|}
\hline & COMET & Nova \\
\hline Size & 100 sq. ft & $>40,000$ sq. ft \\
\hline Cost & $\$ 1 M$ & $>\$ 100 \mathrm{M}$ \\
\hline Pump Energy & $<10 \mathrm{~J}$ & 5 - $10 \mathrm{~kJ}(2$ beams, $1 \omega)$ \\
\hline XRL Gain & $30-65 \mathrm{~cm}^{-1}$ & $1-8 \mathrm{~cm}^{-1}$ \\
\hline XRL Output & $>10 \mu \mathrm{J}(@ 146.8 \mathrm{~A})$ & $5 \mathrm{~mJ}(@ 155 \AA)$ \\
\hline Shot Rate & 50 - 100/day & $4-6 /$ day \\
\hline XRL Wavelength & $119 \AA-330 \AA$ & $35 \AA-330 \AA$ \\
\hline Pulse Duration & $5-10 \mathrm{ps}$ & $45-200$ ps \\
\hline Brightness & $10^{24} \mathrm{ph} \mathrm{mm}^{-2} \mathrm{mrad}^{-2} \mathrm{~s}^{-1}(0.01 \% \mathrm{BW})^{-1}$ & $10^{24} \mathrm{ph} \mathrm{mm}^{-2} \mathrm{mrad}^{-2} \mathrm{~s}^{-1}(0.01 \% \mathrm{BW})^{-1}$ \\
\hline Cost/shot & $\$ 50-100$ & \$10K-20K \\
\hline
\end{tabular}

Table 2 Comparison between the laser driver parameters and $\mathrm{x}$-ray laser characteristics generated by the transient collisional scheme using COMET and the quasi-steady state collisional excitation scheme using the Nova laser.

The authors are pleased to acknowledge the support and encouragement of Mark Eckart during this research. A number of collaborations arose from this work. We acknowledge contributions from Joseph Nilsen (A-Division), Yuelin Li (ILSA), Anatoly Faenov and Tania Pikuz (VNIIFTRI, Russia), Steve Moon and Kevin Fournier (V-Division). Thanks go to Ronnie Shepherd (V-Division) for assistance with the flat-field spectrometer installation and setup. Thanks also to Bart Sellick and Alan Ellis for target fabrication. This work was performed under the auspices of the U.S. Department of Energy by University of California Lawrence Livermore National Laboratory under contract No. W-7405-Eng-48. 


\section{References}

[1] D.L. Matthews, P.L. Hagelstein, M.D. Rosen, M.J. Eckart, N.M. Ceglio, A.U. Hazi, H. Medecki, B.J. MacGowan, J.E. Trebes, B.L. Whitten, E.M. Campbell, C.W. Hatcher, A.M. Hawryluk, R.L. Kauffman, L.D. Pleasance, G. Ramback, J.H. Scofield, G. Stone, and T.A. Weaver, "Demonstration of a soft x-ray amplifier", Phys. Rev. Lett. 54, 110-113 (1985).

[2] L.B. Da Silva, J.E. Trebes, R. Balhorn, S. Mrowka, E. Anderson, D.T. Attwood, T.W. Barbee Jr., J. Brase, M. Corzett, J. Gray, J.A. Koch, C. Lee, D. Kern, R.A. London, B.J. MacGowan, D.L. Matthews, and G. Stone, Science 258, 269 (1992).

[3] L.B. Da Silva, T.W. Barbee Jr., R. Cauble, P. Celliers, D. Ciarlo, S. Libby, R.A. London, D. Matthews, S. Mrowka, J.C. Moreno, D. Ress, J.E. Trebes, A.S. Wan, and F. Weber, Phys. Rev. Lett. 74, 3991 (1995).

[4] D.H. Kalantar, M.H. Key, L.B. Da Silva, S.G. Glendinning, J.P. Knauer, B.A. Remington, F. Weber, and S.V. Weber, Phys. Rev. Lett. 76, 3574 (1996).

[5] B.J. MacGowan, L.B. Da Silva, D.J. Fields, C.J. Keane, J.A. Koch, R.A. London, D.L. Matthews, S. Maxon, S. Mrowka, A.L. Osterheld, J.H. Scofield, G. Shimkaveg, J.E. Trebes, R.S. Walling, "Short wavelength $\mathrm{x}$-ray laser research at the Lawrence Livermore National Laboratory", Phys. Fluids $B$ 4(7), 2326- 2337 (1992).

[6] "X-ray Lasers 1998", Proceedings of the $6^{\text {th }}$ International Conference on X-ray Lasers held in Kyoto, Japan, August 31 - September 4 1998, ed. Y. Kato, H. Takuma, and H. Daido, Institute of Physics Conf. Ser. 159, Bristol and Philadelphia 1999.

[7] "Soft X-ray Lasers and Applications III", ed. J.J. Rocca and L.B. Da Silva, SPIE proc. 3776, Bellingham, WA (1999).

[8] Yu.V. Afanasiev and V.N. Shylaptsev, Sov. J. Quant. Electron. 19, 1606 (1989).

[9] V.N. Shlyaptsev, P.V. Nickles, T. Schlegel, M.P. Kalashnikov, and A.L. Osterheld, "Table-top X-ray laser pumped with subnanosecond and picosecond pulses", SPIE Proceedings 2012, 111-118 (1993).

[10] P.V. Nickles, V.N. Shlyaptsev, M. Kalachnikov, M. Schnürer, I. Will, and W. Sandner, "Short Pulse X-ray Laser at $32.6 \mathrm{~nm}$ Based on Transient Gain in Ne-like Titanium", Phys. Rev. Lett. 78(14), 2748-2751 (1997).

[11] J. Nilsen, B.J. MacGowan, L.B. Da Silva, and J.C. Moreno, Phys. Rev. A 48(6), 4682 (1993); E.E. Fill, Y. Li, G. Pretzler, D. Schlögl, J. Steingruber, and J. Nilsen, Physica Scripta 52, 158 (1995).

[12] Y.L. Li, G. Pretzler, E.E. Fill, and J. Nilsen, Appl. Phys. B 63,125 (1996).

[13] G.J. Linford, E.R. Peressini, W.R. Sooy, and M.L. Spaeth, Appl. Opt. 13(2), 379 (1974).

[14] J. Nilsen, J. Opt. Soc. Am. B 14, 1511 (1997). 


\section{Appendix: Publications related to LDRD work}

1. J. Dunn, A.L. Osterheld, Y. Li, J. Nilsen, and V.N. Shlyaptsev,

"Transient collisional excitation lasers with 1-ps tabletop drivers", in Short Wavelength Lasers and Applications, ed. J.G. Eden and J.J. Rocca, IEEE Journal of Selected Topics in Quantum Electronics 5(6), 1441 - 1446 (1999); University of California Lawrence Livermore National Laboratory, Livermore, CA UCRL-JC-136568 (1999).

2. J. Nilsen, Y. Li, J. Dunn, and A.L. Osterheld, "Modeling psec-laser-driven neon-like titanium x-ray laser experiments", submitted to J. Opt. Soc. Am. B (1999); University of California Lawrence Livermore National Laboratory, Livermore, CA UCRL-JCx (1999).

3. S.J. Moon, J. Dunn, A. Ya Faenov, T.A. Pikuz, K.B. Fournier, A.L. Osterheld, V.N. Shlyaptsev, Y. $\mathrm{Li}$, and J. Nilsen, "Characterization of a High-Gain Ne-like Fe Transient X-ray Laser ", in proceedings of Soft X-ray Lasers and Applications III, ed. J.J. Rocca and L.B. Da Silva, SPIE proc. 3776, p9 - 13, Bellingham, WA (1999); University of California Lawrence Livermore National Laboratory, Livermore, CA UCRL-JC-135728 (1999).

4. J. Dunn, Y. Li, A.L. Osterheld, J. Nilsen, S.J. Moon, K.B. Fournier, J.R. Hunter, A. Ya Faenov, T.A. Pikuz, and V.N. Shlyaptsev, "Table-top transient collisional excitation x-ray lasers", in proceedings of Soft X-ray Lasers and Applications III, ed. J.J. Rocca and L.B. Da Silva, SPIE proc. 3776, p2 - 8, Bellingham, WA (1999); University of California Lawrence Livermore National Laboratory, Livermore, CA UCRL-JC-136567 (1999).

5. Y. Li, J. Dunn, J. Nilsen, T.W. Barbee Jr., L.B. Da Silva, A.L. Osterheld, and V.N. Shlyaptsev, "Near-field imaging of a saturated table-top x-ray laser", in proceedings of Soft X-ray Lasers and Applications III, ed. J.J. Rocca and L.B. Da Silva, SPIE proc. 3776, p45 - 51, Bellingham, WA (1999); University of California Lawrence Livermore National Laboratory, Livermore, CA UCRL-JC134717 (1999).

6. J. Nilsen, Y. Li, J. Dunn, and A.L. Osterheld, "Modeling short-pulse-driven collisional x-ray lasers and other new schemes", in proceedings of Soft X-ray Lasers and Applications III, ed. J.J. Rocca and L.B. Da Silva, SPIE proc. 3776, p14 - 23, Bellingham, WA (1999); University of California Lawrence Livermore National Laboratory, Livermore, CA UCRL-JC-132649 (1999).

7. J. Dunn, J.R. Hunter, B. Sellick and Y. Li, "Reflection echelon optic for traveling wave, transient gain soft X-ray laser", in preparation for submittal to Appl. Opt. (1999); University of California Lawrence Livermore National Laboratory, Livermore, CA UCRL-JC-136566 (1999).

8. J. Dunn, Y. Li, A.L. Osterheld, J. Nilsen, J.R. Hunter, and V.N. Shlyaptsev, "Gain saturation regime for transient Ni-like ion X-ray lasers”, submitted to Phys. Rev. Lett. (1999); University of California Lawrence Livermore National Laboratory, Livermore, CA UCRL-JC-136645 (1999).

9. J. Nilsen, J. Dunn, A.L. Osterheld, and Y. Li,“'Lasing on the self photopumped Ni-like $4 \mathrm{f}^{1} \mathrm{P}_{1}-4 \mathrm{~d}^{1} \mathrm{P}_{1}$ X-ray transition”, Phys. Rev. A 60, R2677 (1999); University of California Lawrence Livermore National Laboratory, Livermore, CA UCRL-JC-134368 (1999).

10. Y. Li, J. Dunn, J. Nilsen, A.L. Osterheld, and V.N. Shlyaptsev, "A saturated table-top X-ray laser system at $19 \mathrm{~nm}$ ", submitted to J. Opt. Soc. Am. B (1999); University of California Lawrence Livermore National Laboratory, Livermore, CA UCRL-JC-x (1999).

11. J. Dunn, J. Nilsen, A.L. Osterheld, Y. Li, and V.N. Shlyaptsev, "Demonstration of transient gain x-ray lasers near $20 \mathrm{~nm}$ for nickellike $\mathrm{Y}, \mathrm{Zr}, \mathrm{Nb}$, and Mo", Opt. Lett. 24, 101 (1999); University of California Lawrence Livermore National Laboratory, Livermore, CA UCRL-JC-128707 (1999).

12. J. Dunn, A.L. Osterheld, R. Shepherd, W.E. White, V.N. Shlyaptsev, and R.E. Stewart, 
"Demonstration of X-ray Amplification in Transient Gain Nickel-like Palladium Scheme", Phys. Rev. Lett. 80(13), 2825 (1998).

13. J. Dunn, A.L. Osterheld, V.N. Shlyaptsev, J.R. Hunter, R. Shepherd, W.E. White, and R.E. Stewart, "High Gain X-ray Lasers Pumped by Transient Collisional Excitation", Atomic Processes in Plasmas: 11th APS Topical Conference, Auburn, AL, 22 - 26 March 1998, ed. E.Oks, and M.S. Pindzola, CP443, p 106 American Institute of Physics (1998).

14. J. Dunn, V.N. Shlyaptsev, A.L. Osterheld, W.E. White, R. Shepherd, and R.E. Stewart, "Determination of transient gain lifetime for a 1-ps driven nickellike palladium $14.7 \mathrm{~nm}$ laser", Lawrence Livermore National Laboratory, Livermore, CA UCRL-JC-131413 (1998).

15. Y. Li, J. Nilsen, J.Dunn, A.L. Osterheld, A. Ryabtsev, and S. Churilov, "Wavelengths of the Ni-like $4 d^{1} S_{0}-4 p{ }^{1} P_{1}$ x-ray laser line", Phys. Rev. A 58, R2668 (1998).

16. A.L. Osterheld, J. Dunn, and V.N. Shlyaptsev, "Characterization of transient gain $x$-ray lasers", in proceedings of 6th International Conference on X-ray Lasers, Kyoto, Japan August 31 - September 4, 1998 Institute of Physics Conference Series 159, 131 (1998).

17. J. Dunn, A.L. Osterheld, V.N. Shlyaptsev, Y. Li, J. Nilsen, R. Shepherd, and L.B. Da Silva, "Progress in table-top transient collisional excitation $x$-ray lasers at LLNL", in proceedings of 6th International Conference on X-ray Lasers, Kyoto, Japan August 31 - September 4, 1998 Institute of Physics Conference Series 159, 51 (1998).

18. J. Nilsen, Y. Li, J. Dunn, A.L. Osterheld, A. Ryabtsev, and S. Churilov, "Measuring the wavelengths of the Ni-like $4 d^{1} S_{0}-4 p{ }^{1} P_{1} x$-ray laser line", in proceedings of 6th International Conference on X-ray Lasers, Kyoto, Japan August 31 - September 4, 1998 Institute of Physics Conference Series 159, 135 (1998).

19. J. Nilsen, Y. Li, J. Dunn, and A.L. Osterheld, "Progress in understanding the short-pulse-driven collisional x-ray lasers", in proceedings of 6th International Conference on X-ray Lasers, Kyoto, Japan August 31 - September 4, 1998 Institute of Physics Conference Series 159, 123 (1998).

20. A.L. Osterheld, V.N. Shlyaptsev, J. Dunn, J.J. Rocca, M.C. Marconi, C.H. Moreno, J.J. Gonzales, M. Frati, P.V. Nickles, M.P. Kalashnikov, and W. Sandner , "Modeling of laser-produced plasma and Zpinch x-ray lasers", in proceedings of 6th International Conference on X-ray Lasers, Kyoto, Japan August 31 - September 4, 1998, Institute of Physics Conference Series 159, 353 (1998).

21. A.L. Osterheld, B.K.F. Young, J. Dunn, R.E. Stewart, I. Yu. Skobelev, A. Ya. Faenov, A.I. Magunov, "Influence of Laser Satellite Transitions on Spectroscopy of High-Intensity Laser-Produced Plasmas", JQSRT 58, 827 (1997).

22. J. Dunn, A.L. Osterheld, R. Shepherd, W.E. White, V.N. Shlyaptsev, and R.E. Stewart, "Table-Top Transient Collisional Excitation X-ray Laser Research at LLNL: Status June 1997", Lawrence Livermore National Laboratory, Livermore, CA UCRL-ID-127872 (1997).

23. J. Dunn, A.L. Osterheld, R. Shepherd, W.E. White, V.N. Shlyaptsev, A.B. Bullock, and R.E. Stewart, "Table-top transient collisional excitation X-ray laser research at LLNL", in proceedings of Soft X-ray Lasers and Applications II, ed. J.J. Rocca and L.B. Da Silva, SPIE proc. 3156, 114, Bellingham, WA (1997).

24. V.N. Shlyaptsev, J.J. Rocca, M.P. Kalachnikov, P.V. Nickles, W. Sandner, A.L. Osterheld, J. Dunn, and D.C. Eder, "Modeling of table-top transient inversion and capillary $\mathrm{x}$-ray lasers", in proceedings of Soft X-ray Lasers and Applications II, ed. J.J. Rocca and L.B. Da Silva, SPIE proc. 3156, 193, Bellingham, WA (1997). 